\title{
CARTOGRAFIA DE RISCO DE MALÁRIA NO MUNICÍPIO DE MAXIXE: CASO DO BAIRRO CHAMBONE
}

\author{
ARTIGO ORIGINAL \\ CHITATA, Joaquim Gome André ${ }^{1}$ \\ DGEDGE, Gustavo Sobrinho ${ }^{2}$
}

CHITATA, Joaquim Gome André. DGEDGE, Gustavo Sobrinho. Cartografia de risco de malária no Município de Maxixe: Caso do Bairro Chambone. Revista Científica Multidisciplinar Núcleo do Conhecimento. Ano 05, Ed. 05, Vol. 06, pp. 139-154. Maio de 2020. ISSN: 2448-0959, Link de acesso: https://www.nucleodoconhecimento.com.br/geografia/cartografia-de-risco

\section{RESUMO}

O presente artigo cinge-se na avaliação da espacialização do risco de malária, com base em dados de áreas residenciais por tipo de criadouros do bairro Chambone (Maxixe, Moçambique). Para a operacionalização dos objetivos, optou-se, além da revisão bibliográfica, por uma abordagem quali-quantitativa, por observações acompanhadas e inquéritos. Os resultados revelam que as áreas de alto risco de malária em Chambone são os extremos nordeste, centro-oriental, meridional e interior sudoeste-central. Estas áreas de alto risco, conforme a reclassificação dada pela densidade de Kernel, são de maior concentração de criadouros e habitações. Dada a diversidade no padrão de distribuição espacial do risco e aos fatores com condicionantes, tendo em conta o tipo de planificação para a totalidade das áreas do

\footnotetext{
${ }^{1}$ Mestrado em Gestão Ambiental e Licenciado em Ensino de Geografia.

2 Doutor em Ciências Ambientais (PhD), Mestrado em Gestão de Resíduos e Licenciado em Geografia e História.
} 
bairro Chambone, revelou-se viável a elaboração de planos ajustados aos interesses locais para modificação do atual padrão espacial da distribuição do risco da malária.

Palavras-chave: Cartografia, análise espacial, riscos ambientais, malária.

\section{INTRODUÇÃO}

A malária é uma doença infecciosa, febril, aguda ou crônica, sistêmica, não contagiosa, causada pelos parasitas do gênero Plasmodium e transmitida pela picada do mosquito Anopheles (Ávila, 1996; Garcia et al, 2009; Nweti, 2010). No território moçambicano, este parasita é responsável por cerca de $90 \%$ de casos de malária e pode ser transmitido a homens e mulheres de todas as idades. Segundo a Roll Back Malaria (RBM, 2008, 2014) e a OMS (2014), no seu relatório "Global Malaria Action Plan", na África a maior parte das mortes aglomera-se em somente 35 países, sendo que, deste número, apenas cinco são responsáveis por $50 \%$ das mortes em todo mundo e por $47 \%$ de todos os casos de malária, sendo esses países o Burquina Faso, a Nigéria, a República Democrática de Congo, a Uganda, a Etiópia, o Mali, o Malawi, Moçambique e a Tanzânia (figura 1).

Figura 1: Mapa da espacialização do risco da malária no mundo, OMS (2014)

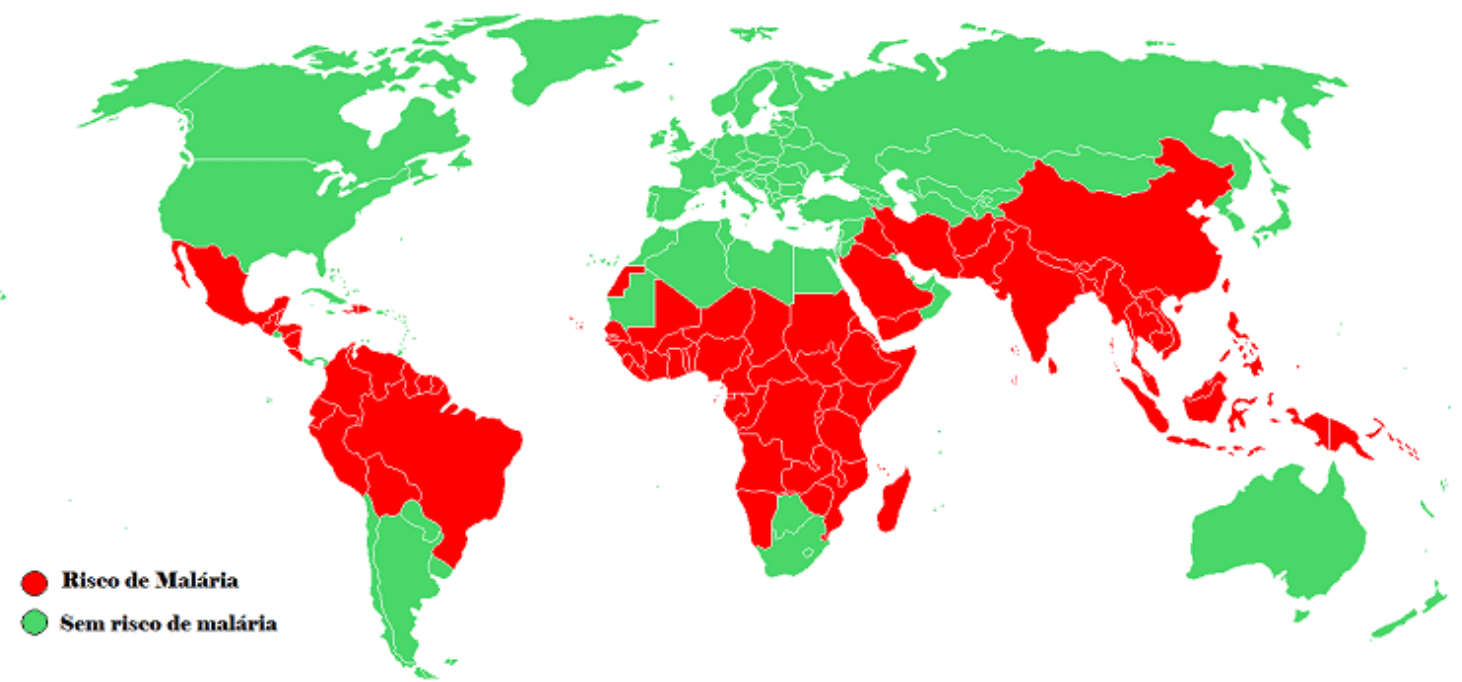

Fonte: OMS (2014) 
Em Moçambique, a malária afeta mais as comunidades das áreas rurais e urbanas pobres pela carência de informação e de medidas de precaução, com elevadas taxas de transmissão e dificuldades para acesso aos serviços básicos de saúde, conduzindo, dessa forma, à morte de cerca de 3,9\% de população infantil e $6,2 \%$ de população adulta (WHO, 2004). Moçambique é considerado um território de risco de malária, devido à localização geográfica que se encontra: numa região tropical onde a malária é uma doença endêmica resultado do favorecimento do clima na sua transmissão ao logo de quase todo ano, atingindo o seu pico máximo após a época chuvosa (dezembro a abril).

Esta questão repercute-se na intensidade da transmissão que varia de ano a ano e de região a região, dependendo da temperatura, precipitação e altitude. Porém, algumas áreas secas do território nacional são tidas como pouco propensas à epidemia e havia, em 2008, a esperança de que até 2011 a vacina contra malária estivesse disponível para salvar vidas (MISAU, 2008). De acordo com SSMAS (2016), o município de Maxixe registou cerca de 46.773 casos notificados de malária, um número expressivamente alto quando comparado com outras áreas geográficas do país, sendo que esta doença é responsável pelos elevados índices de mortalidade neste município.

Assim, o estudo constitui um dos subsídios para a planificação do setor da saúde e da gestão territorial, contribuindo, portanto, para o desenvolvimento sustentável. Portanto, o fato de o município de Maxixe se situar numa região tropical onde há maior probabilidade do desenvolvimento do vetor causador da malária, tornando-a, assim, uma região de risco de malária, aliado ao modo de vida dos residentes do bairro Chambone, que se submetem a um contato constante com os epicentros de doenças (criadouros), pneus usados como vedação, car wash, lixeiras, oficinas, cursos de água, arquétipo de moradias, entre outros, pode dificultar o controle de vetores e potencializar a transmissão da doença.

O município da Maxixe coincide com a mesma área ocupada pelo traçado do distrito de Maxixe em termos de limites de jurisdição político-administrativa e faz parte do território moçambicano, localizado na costa sudeste da baía de Inhambane, onde se 
enquadra o bairro Chambone, ocupando uma área de cerca de $12,6 \mathrm{Km}^{2}$, localizado na região central, uma das áreas mais privilegiadas em termos geoestratégicos, encontrando-se entre as coordenadas $23^{\circ} 51^{\prime} 30^{\prime \prime}$ e $23^{\circ} 52^{\prime} 10^{\prime \prime}$ de latitude Sul, e $35^{\circ}$ $18^{\prime} 00^{\prime \prime}$ e $35^{\circ} 21^{\prime} 15^{\prime \prime}$ de longitude Este (figura 2). Os dados podem ser melhor visualizados a seguir:

Figura 2: Mapa do Enquadramento Geográfico da Área de Estudo

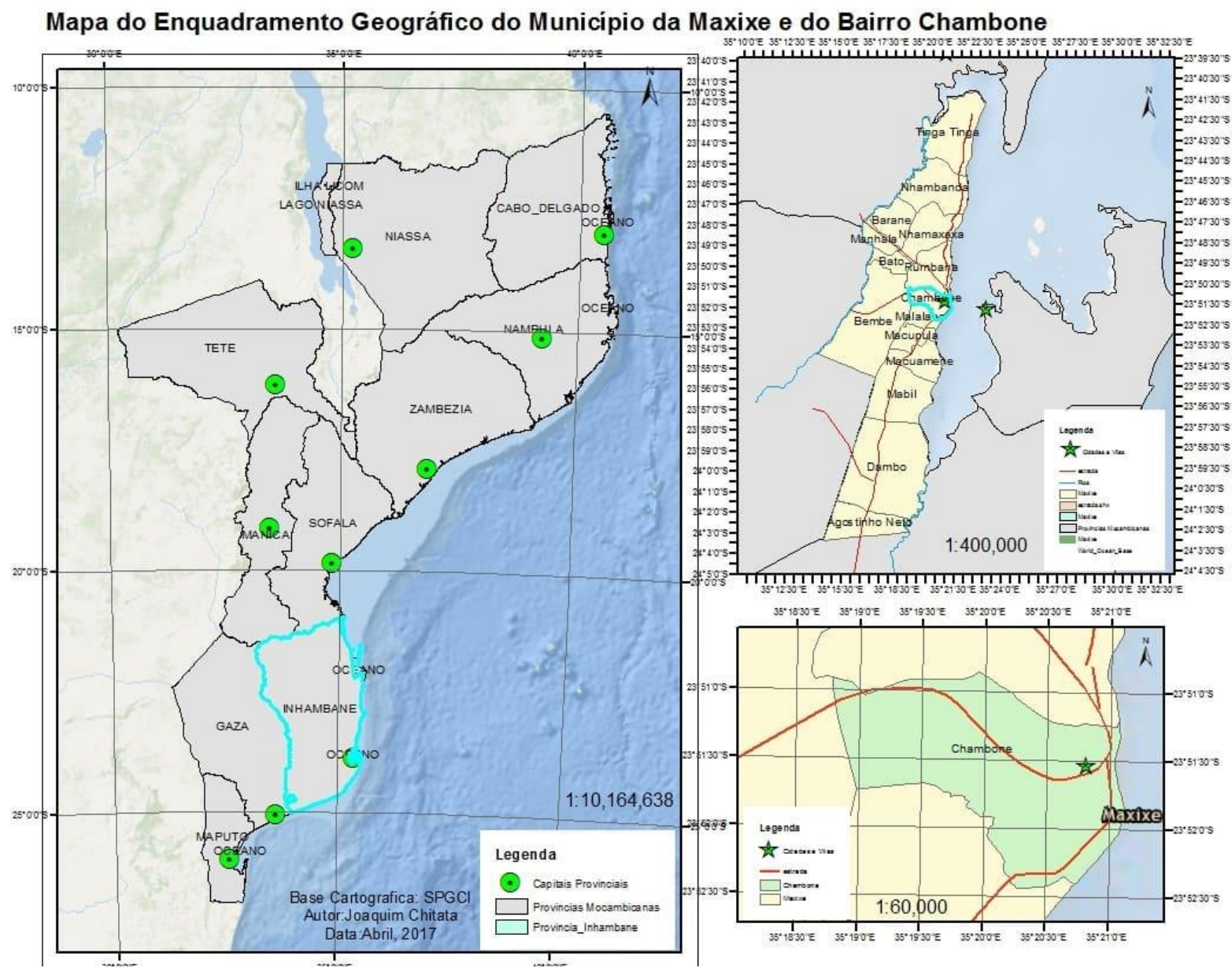

Fonte: Autor (2017)

O trabalho embasou-se na abordagem quali-quantitativa, pesquisa bibliográfica e documental para entendimento dos conceitos básicos do tema, fez-se, também, observações acompanhadas por levantamentos geodésicos e um estudo descritivo acerca da situação ambiental dos diferentes assentamentos do bairro Chambone, no período de janeiro de 2016 a abril de 2017. Os inquéritos tiveram como plano de 
amostragem 345 agregados familiares extraídos de um universo de cerca de 2.500 agregados familiares. Para validar as características do lugar, foram elaborados mapas, gráficos, tabelas e outros dados secundários relacionados ao risco da malária. Sendo assim, são apresentadas, de forma sintética, as etapas de realização das atividades da presente pesquisa, ilustradas no fluxograma (figura $3^{[3] 2345}$ ):

Figura 3: Fluxograma da metodologia de pesquisa

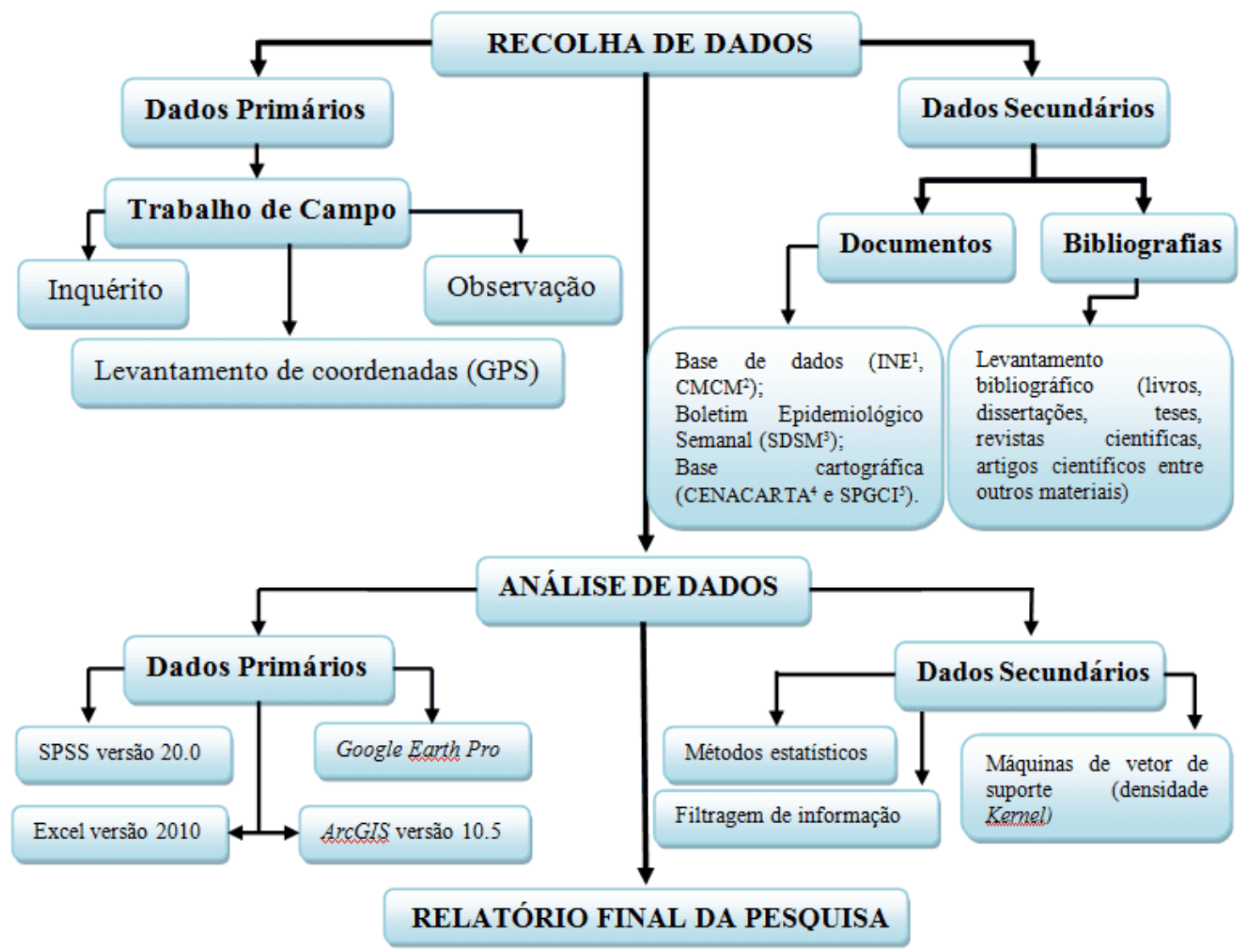

Fonte: Autor (2017)

\section{RESULTADOS E DISCUSSÃO}

A caracterização do bairro Chambone contempla aspectos socioambientais que se referem à probabilidade e severidade dos níveis de risco de malária e baseou-se em elementos do inquérito como: (i) época do ano, frequência de casos de malária e ambiente físico-variáveis cruzadas. Tais elementos evidenciaram que a maior parte 
dos casos $(53,6 \%)$ ocorreram no verão, visto que é neste período em que os índices pluviométricos registados ao longo do ano são elevados (meio físico mais ou menos saudável), condicionando a ativação e surgimento de novos criadouros (tabela 1); (ii) comportamentos que deixam os residentes expostos ao mosquito, tendo em conta que a maior parte das pessoas veem a TV e escutam a rádio com portas e janelas abertas, cerca de $36,5 \%$ e o menor número de respostas refere-se à prática da agricultura com cerca de 6,2\%, como ilustra a tabela 2; (iii) medidas de prevenção de malária: os resultados evidenciam que os residentes optam mais pelo uso de redes mosquiteiros e repelentes, com $48.3 \%$ e $22.3 \%$, respectivamente (tabela 3 ).

Tabela 1: Época do ano e frequência de casos de malária e ambiente físico do bairro

\begin{tabular}{|c|c|c|c|c|c|c|c|}
\hline & \multicolumn{4}{|c|}{$\begin{array}{l}\text { Ambiente físico do bairro em que } \\
\text { vive (clima, poluição, etc) }\end{array}$} & \multirow[t]{2}{*}{ Total } \\
\hline & & & $\begin{array}{l}\text { Não } \\
\text { saudável }\end{array}$ & $\begin{array}{l}\text { Muito } \\
\text { pouco }\end{array}$ & $\begin{array}{l}\text { Mais } \\
\text { ou } \\
\text { menos }\end{array}$ & Bastante & \\
\hline \multirow{4}{*}{$\begin{array}{l}\text { Época do } \\
\text { ano e } \\
\text { frequência } \\
\text { de casos } \\
\text { de malária }\end{array}$} & \multirow[t]{2}{*}{ Verão } & Count & 34 & 89 & 158 & 14 & 295 \\
\hline & & $\begin{array}{l}\% \\
\text { within }\end{array}$ & $11.5 \%$ & $30.2 \%$ & $53.6 \%$ & $4.7 \%$ & $100.0 \%$ \\
\hline & \multirow[t]{2}{*}{ Inverno } & Count & 1 & 6 & 20 & 20 & 47 \\
\hline & & $\begin{array}{l}\% \\
\text { within }\end{array}$ & $2.1 \%$ & $12.8 \%$ & $42.6 \%$ & $42.6 \%$ & $100.0 \%$ \\
\hline \multirow{2}{*}{\multicolumn{2}{|c|}{ Total }} & Count & 35 & 95 & 178 & 34 & 342 \\
\hline & & $\begin{array}{l}\% \\
\text { within }\end{array}$ & $10.2 \%$ & $27.8 \%$ & $52.0 \%$ & $9.9 \%$ & $100.0 \%$ \\
\hline
\end{tabular}

Fonte: Autor (2017)

Tabela 2: Comportamentos que deixam os residentes expostos ao mosquito

\section{Responses}




\begin{tabular}{|l|l|l|l|}
\hline $\begin{array}{l}\text { Comportamentos que deixa os } \\
\text { residentes expostos ao mosquito } \\
\text { durante o verão }\end{array}$ & $N$ & Percent & $\begin{array}{l}\text { Percent } \\
\text { Cases }\end{array}$ \\
\hline $\begin{array}{l}\text { Conversa fora das residências } \\
\text { Ver a TV e escutar a rádio com portas } \\
\text { e janelas abertas }\end{array}$ & 121 & $27.8 \%$ & $35.3 \%$ \\
\hline $\begin{array}{l}\text { Deitar-se no quintal e por baixo das } \\
\text { árvores durante a noite }\end{array}$ & 129 & $36.5 \%$ & $46.4 \%$ \\
\hline $\begin{array}{l}\text { Prática de agricultura } \\
\text { Total }\end{array}$ & 27 & $29.6 \%$ & $37.6 \%$ \\
\hline
\end{tabular}

Fonte: Autor (2017)

Tabela 3: Medidas de prevenção de malária

\begin{tabular}{|c|c|c|c|}
\hline \multirow{2}{*}{$\begin{array}{l}\text { Medidas de prevenção } \\
\text { da malária }\end{array}$} & \multicolumn{2}{|c|}{ Responses } & \multirow[t]{2}{*}{ Percent of Cases } \\
\hline & $\mathrm{N}$ & Percent & \\
\hline Rede mosquiteira & 210 & $48.3 \%$ & $61.0 \%$ \\
\hline Repelentes & 97 & $22.3 \%$ & $28.2 \%$ \\
\hline Pulverização & 60 & $13.8 \%$ & $17.4 \%$ \\
\hline $\begin{array}{ll}\text { Eliminação } & \text { de } \\
\text { charcos/capim } & \end{array}$ & 68 & $15.6 \%$ & $19.8 \%$ \\
\hline Total & 435 & $100.0 \%$ & $126.5 \%$ \\
\hline
\end{tabular}

Fonte: Autor (2017)

Prosseguindo, (iv) refere-se à forma de construção das moradias, que pode contribuir, de modo expressivo, para com a propagação do mosquito causador da malária, devido à falta de janelas e paredes em algumas moradias, sendo que cerca de $72,1 \%$ das residências apresentam paredes completas, constituindo o maior número de agregados familiares com habitações fora da situação dos elementos sob risco (figura 4); (v) a percepção da população em relação ao risco de malária posiciona-se na condição de médio e alto risco, com 41,7\% e 35,6\%, respectivamente. Esta situação 
revela que apenas $22,7 \%$ do total da população se encontra numa situação de baixo risco e sem risco (figura 5).

Figura 4: Caracterização das paredes das moradias

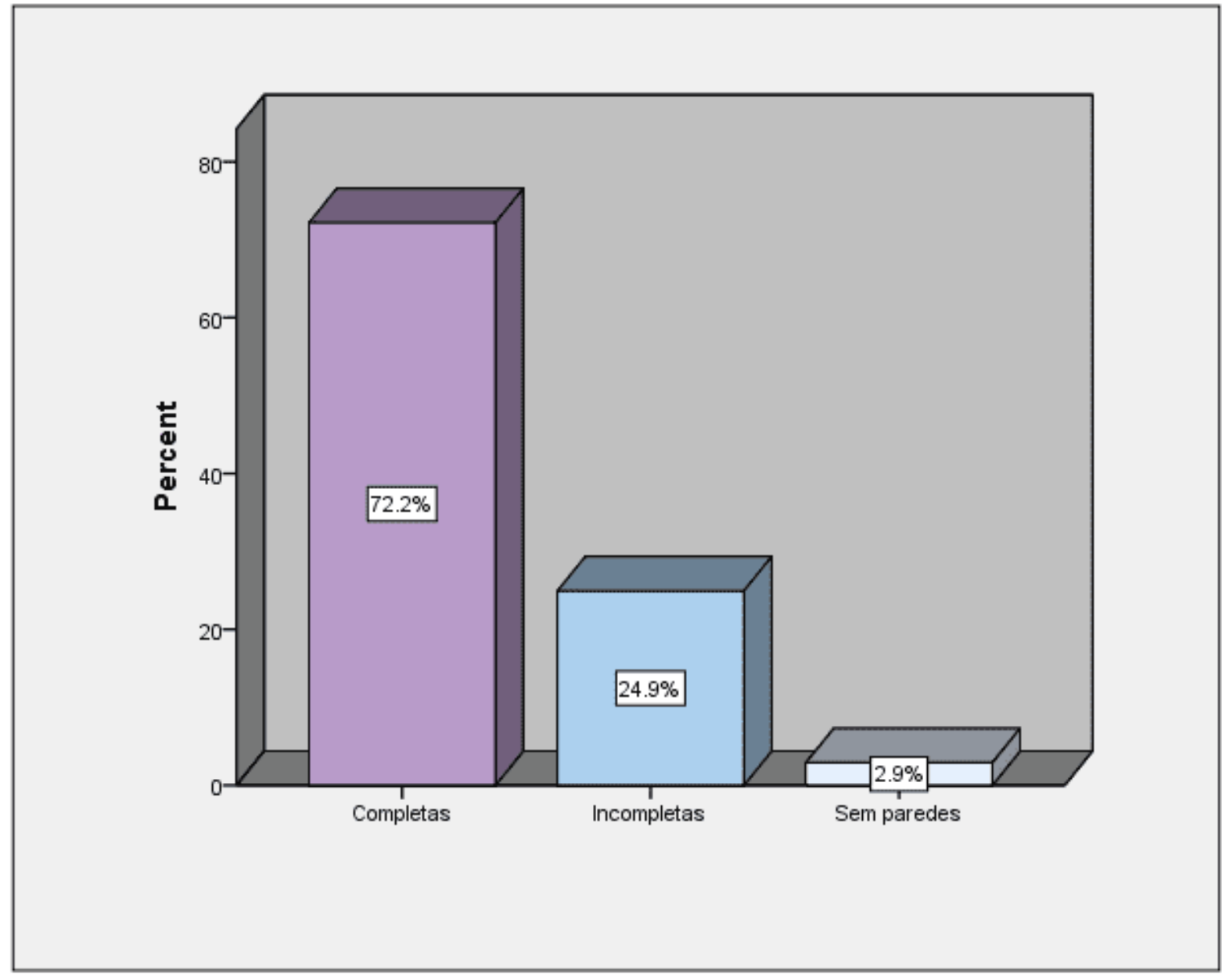

Fonte: Autor (2017) 
Figura 5: Percepção em relação ao risco da malária

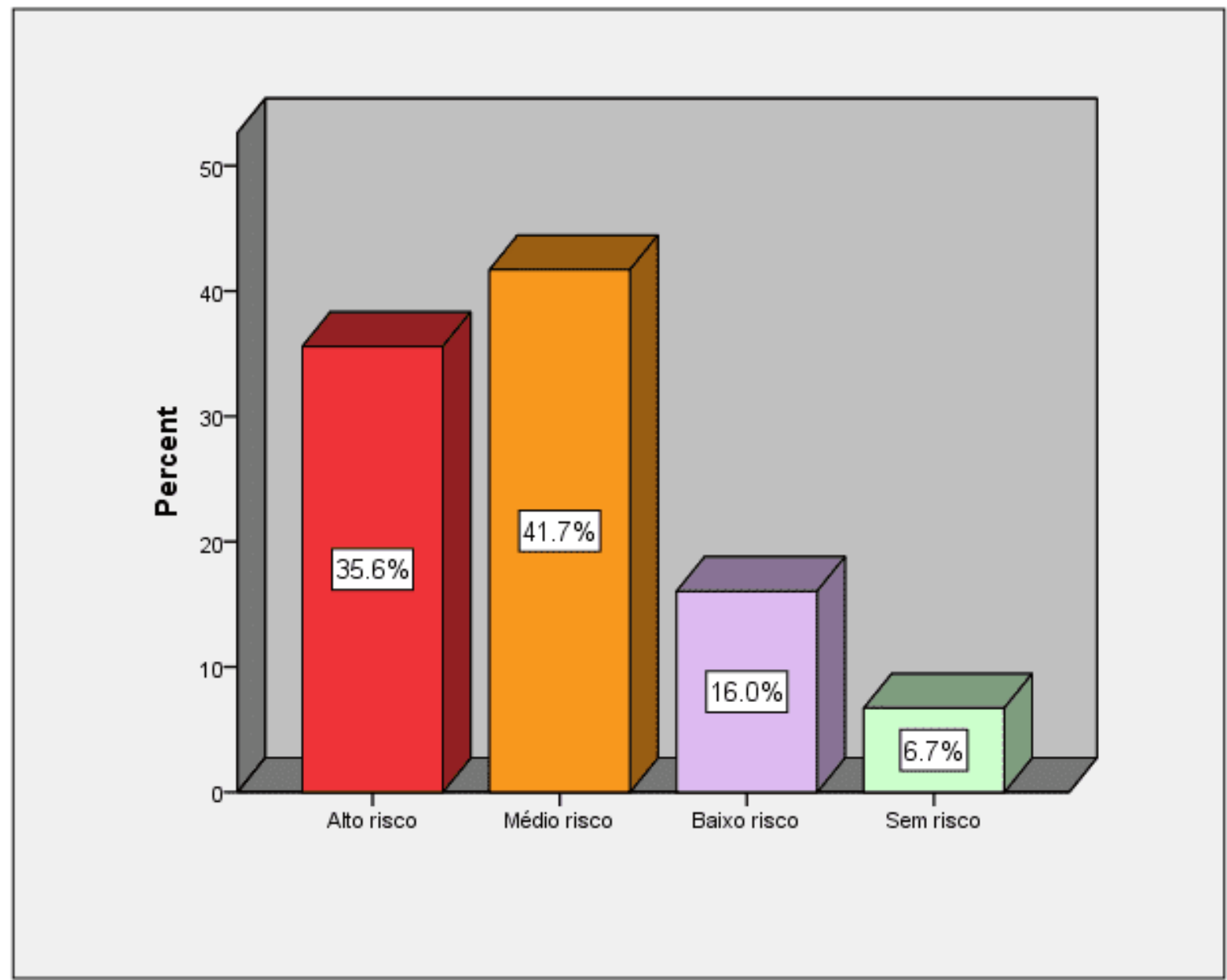

Fonte: Autor (2017)

A análise de informações espaciais requer uma particularidade consoante à tipologia dos dados a serem apresentados, sendo que estes podem ser pontos (localização dos criadouros) e das áreas com contagem (número de habitações). A representação por uma superfície habitacional, classificada a partir dos níveis de densidade que alternam conforme com a cor e tonalidade, foi interpretada da seguinte forma: vermelho significa densidade muito alta; Iaranja indica a densidade alta; o amarelo refere-se à densidade média; o verde com tonalidade mais clara concerne à densidade baixa e o verde com tonalidade mais escura denota uma densidade muito baixa. A superfície gerada em relação à população apresenta valores de 0 a mais de 2500 habitantes por quilômetro quadrado (hab/km²), como ilustra a figura 6 . 
O extremo Setentrional-Central-Meridional da parte Oriental do bairro Chambone, apresenta maior concentração de habitações, o que significa muito alta e alta densidade populacional e varia de 1000 a mais de $2500 \mathrm{hab} / \mathrm{km}^{2}$. Essa muito alta e alta densidade populacional, deve-se ao fato de ser uma área urbana, onde está localizada a sede do município da Maxixe, o qual apresenta maior concentração populacional, quando comparado às outras áreas. Mais para o interior do bairro, concretamente no extremo central sudoeste em relação a área mais urbanizada, encontramos um pequeno aglomerado que constitui uma área de alta e média densidade, com variações de 500 a $2500 \mathrm{hab} / \mathrm{km}^{2}$.

Figura 6: Mapa do padrão de distribuição espacial da densidade de habitações

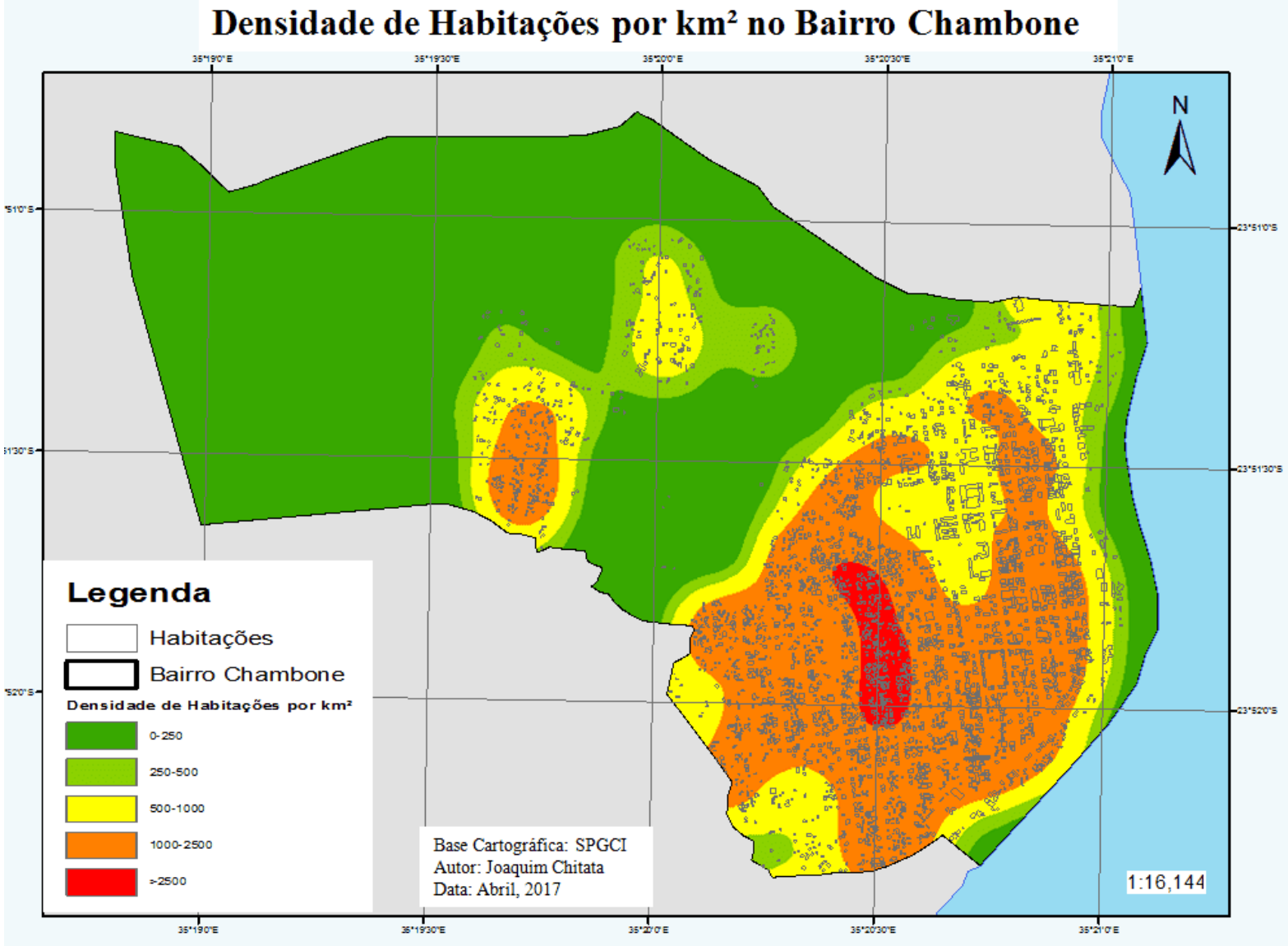

Fonte: Autor (2017) 
A qualificação do mapa do padrão de distribuição espacial da densidade dos criadouros/focos de malária (figura 7) foi feita tendo atenção à cor e tonalidade, representadas por quatro (04) criadouros de densidades, distribuídos por 332 pontos georreferenciados e definidos pela proximidade/vizinhança que varia de 0 a mais de 100 criadouros, com a seguinte atribuição: vermelho significa densidade muito alta; laranja indica densidade alta; verde com tonalidade mais clara implica densidade média e verde com tonalidade mais escura refere-se à densidade baixa. Analisando o mapa do padrão de distribuição espacial da densidade dos criadouros, percebe-se que estes estão distribuídos em quase todo o bairro Chambone, sendo que as áreas de densidade muito alta (mais de 100) e alta (50 a 100) de criadouros se encontram no extremo setentrional-central.

Figura 7: Mapa do padrão de distribuição espacial da densidade de Criadouros por proximidade

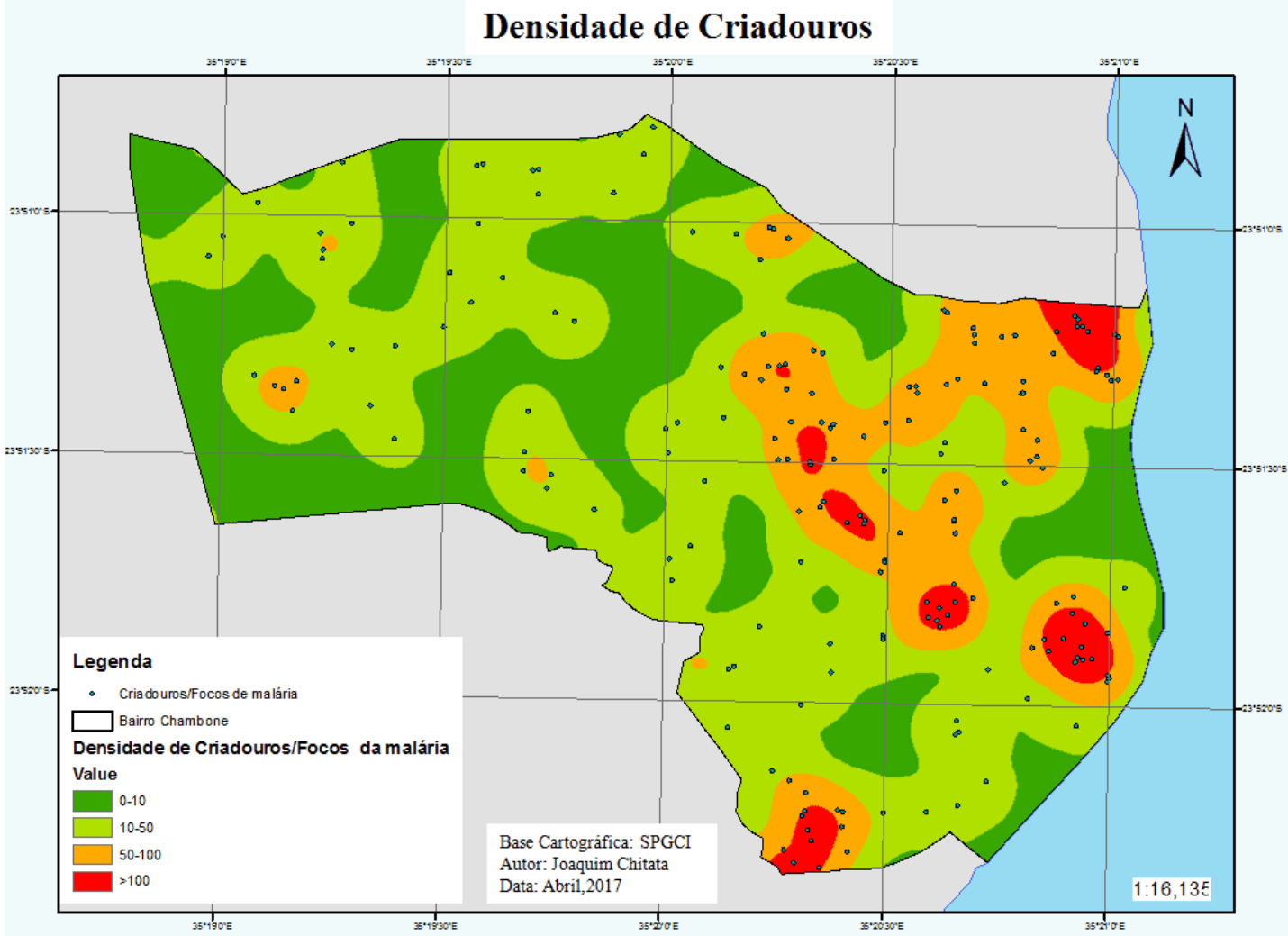

Fonte: Autor (2017) 
O processo de representação esquemática do procedimento da reclassificação dos criadouros passa para um outro passo fundamental com vista a obter informações de densidade de criadouros por $\mathrm{Km}^{2}$ no bairro, qualificadas a partir da horizontalidade da densidade, de acordo com a cor e tonalidade, esclarecidas da seguinte forma: verde com tonalidade mais escura concerne à densidade muito baixa; verde com tonalidade mais clara significa densidade baixa; amarelo é da densidade média; laranja indica densidade alta e vermelho implica a densidade muito alta (figura 8).

Para analisar a situação de densidade dos criadouros por $\mathrm{km}^{2}$ na área de estudo, partiu-se para uma categorização da densidade Kernel em cinco (05) níveis, já referenciados no parágrafo anterior, sendo uma superfície que resulta de densidades muito altas (mais de $\left.2,5 \mathrm{Km}^{2}\right)$ e alta $\left(1-2,5 \mathrm{Km}^{2}\right)$ de criadouros. Estes encontram-se no extremo setentrional-central, oriental-central e meridional. É também notável a predominância da densidade média na maior parte da superfície do bairro Chambone.

Figura 8: Mapa do padrão de distribuição espacial da densidade de Criadouros por $\mathrm{Km}^{2}$

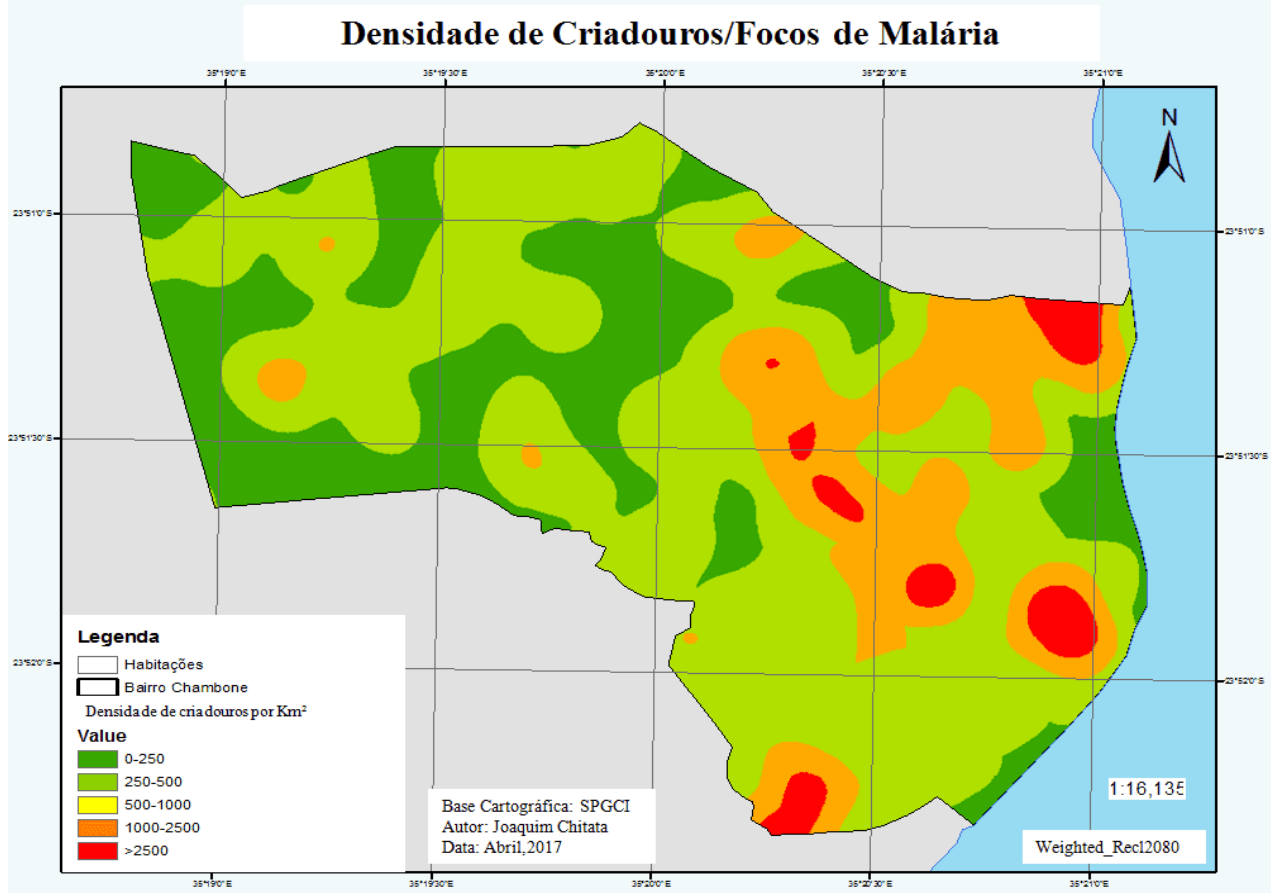

Fonte: Autor (2017) 
Houve a necessidade da reclassificação das habitações recorrendo ao mapa da densidade de Kernel da proximidade de habitações, apresentando níveis de densidades (1 à 5), sendo que o nível cinco, representado pela cor vermelha, indica a maior proximidade entre as habitações no bairro Chambone (figura 9). Esta proximidade ou vizinhança de habitações evidencia uma maior concentração da população nestas áreas, indicativo essencial que requer atenção no processo de análise do risco de malária. A preocupação com a análise espacial para o presente estudo serviu de ferramenta para georreferenciar as áreas de risco do bairro Chambone e para identificar os fatores associados ao padrão espacial do risco de malária.

É nesta ordem de ideias que se procurou a localização exata de áreas de risco, distância entre criadouros ou focos de malária e habitações. A evidência da localização de concentrações de maior número de criadouros em áreas habitacionais ou próximas é fundamental à análise ao nível do bairro, o que permite a identificação de áreas com prioridade para intervenção das autoridades locais.

Figura 9: Mapa do padrão de distribuição espacial da densidade de habitações por proximidade

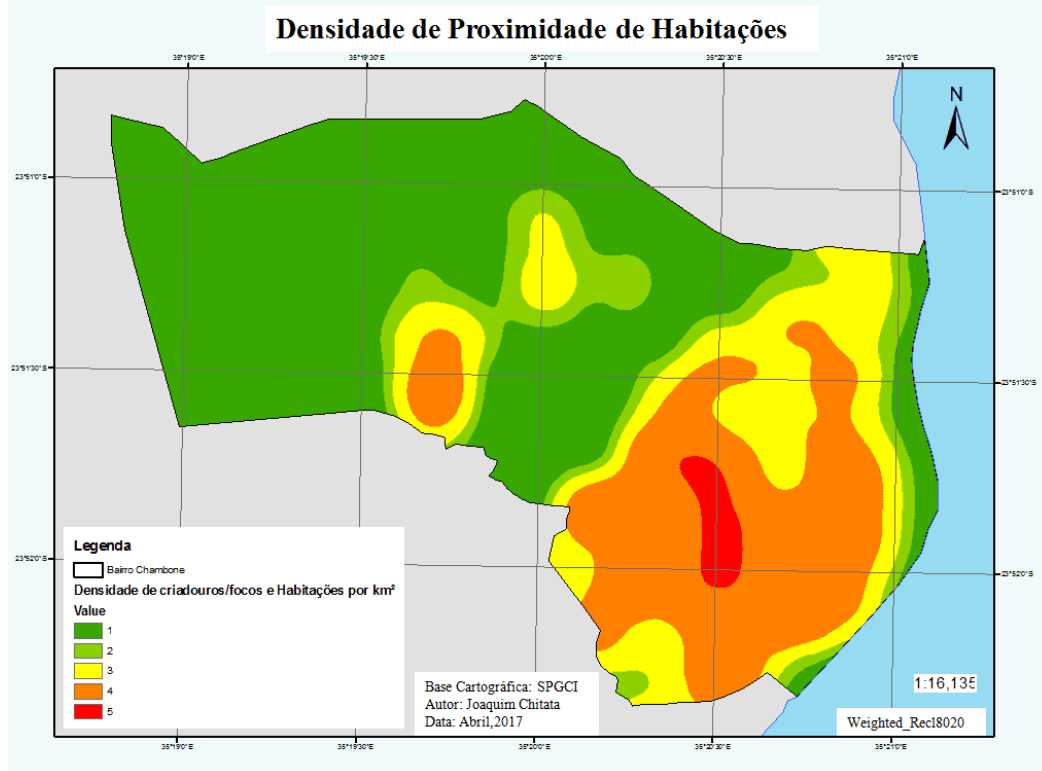

Fonte: Autor (2017) 
Para uma melhor leitura, análise e interpretação do mapa Kernel (figura 10), foram classificados os Layers, com base em níveis de risco que variam a partir de fatores definidos pela cor e tonalidade, interpretados da seguinte forma: vermelho significa alto risco; laranja indica médio; verde com tonalidade mais clara significa baixo e verde com tonalidade mais escura significa que há risco. A estrutura lógica da linguagem cartográfica apresentada para a avaliação da espacialização do risco da malária no bairro Chambone permite de forma bem rápida, clara e eficaz a percepção acerca da real situação.

Estas informações qualificam-se por meio de outros agregados de dados, pois, nas observações, encontram-se, sempre, as referências para identificar e qualificar a área de estudo. Um conjunto de informações espaciais sobre o risco epidemiológico pode incluir não somente observações dos eventos de saúde, como, também, informações sobre o local d'onde foram coletados (BARATA, 1997), isto é, além do ambiente físico, podem-se tomar as suas complexas interações com aspectos sociais, culturais e econômicos do local.

Figura 10: Mapa da avaliação espacial do risco da malária no bairro Chambone

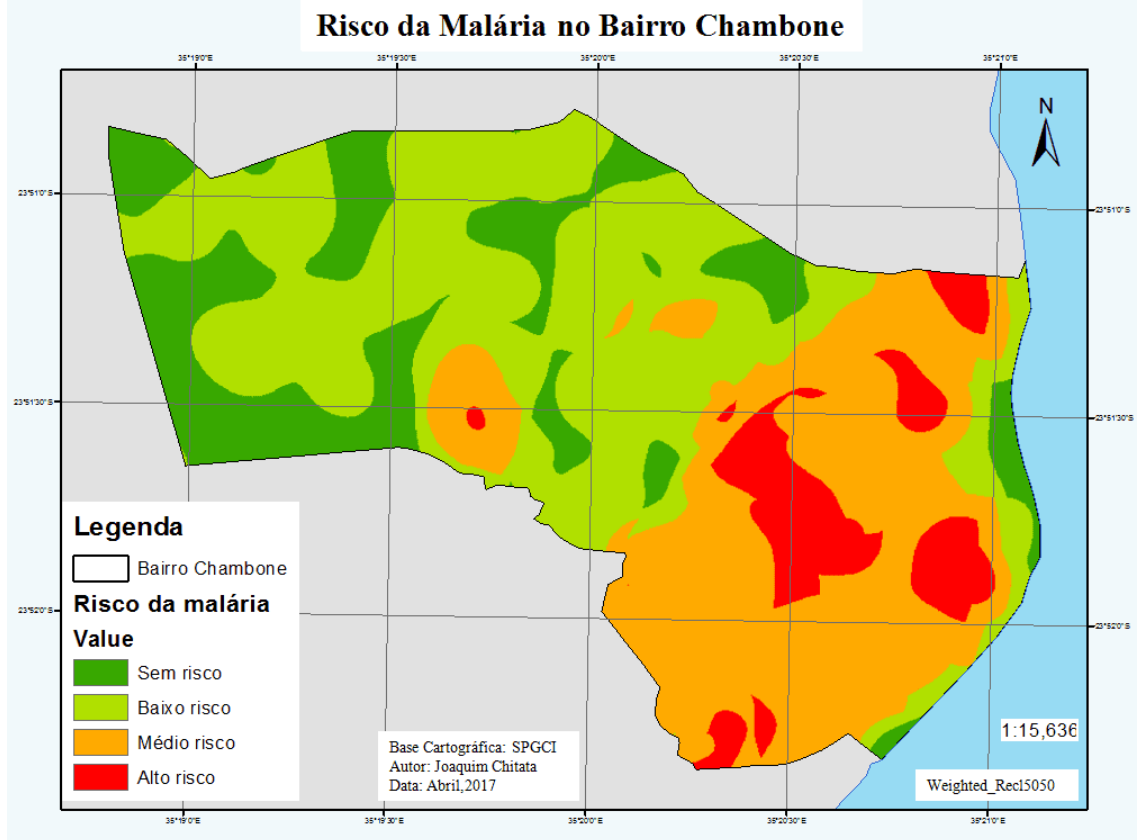

Fonte: Autor (2017) 
A questão de riscos sempre esteve associada ao homem pois a sua presença num determinado lugar torna-se prioritária em caso de um evento. Foi neste sentido que, ao definir-se as áreas de risco no bairro Chambone, pautou-se pelo resultado da conjugação de duas componentes: a primeira da enérgica do meio geofísico que abrange o perigo devido à presença humana e a segunda advém da exposição dos habitantes em conexão aos perigos derivados dessa enérgica, o que Ihes coloca na condição de vulnerabilidade. Portanto, os estudos da relação espacial entre os dados do risco da malária contribuíram, de forma significativa, para uma melhor compreensão do fenômeno em análise. As áreas de alto risco da malária no bairro Chambone são os extremos Nordeste, Centro-Oriental, Meridional e interior ao Sudoeste central.

Este resultado ilustra que estas áreas possuem maior concentração de criadouros e habitações, sendo, assim, estabelecidas áreas de alto risco, conforme a reclassificação dada pela densidade de Kernel. Para dar mais subsídios à distribuição espacial do risco da malária no bairro Chambone, optou-se pelo uso de uma cartaimagem a fim de ilustrar as áreas de alto risco, concentrados no extremo nordeste, central-oriental, sudoeste e meridional (figura 11). Estas são algumas evidências da realidade socioambiental da área de estudo. No extremo nordeste está assente uma lagoa revestida de vegetação de caniço, capim e arbustos. Esta lagoa tem continuidade ao longo da costa oriental, constituída por uma vegetação de mangal e pequenos arbustos, intercalados por águas estagnadas, lixeiras, pneus usados como vegetação, entre outros. 
Figura 11: Carta-Imagem das Áreas de Alto Risco da Malária no Bairro Chambone

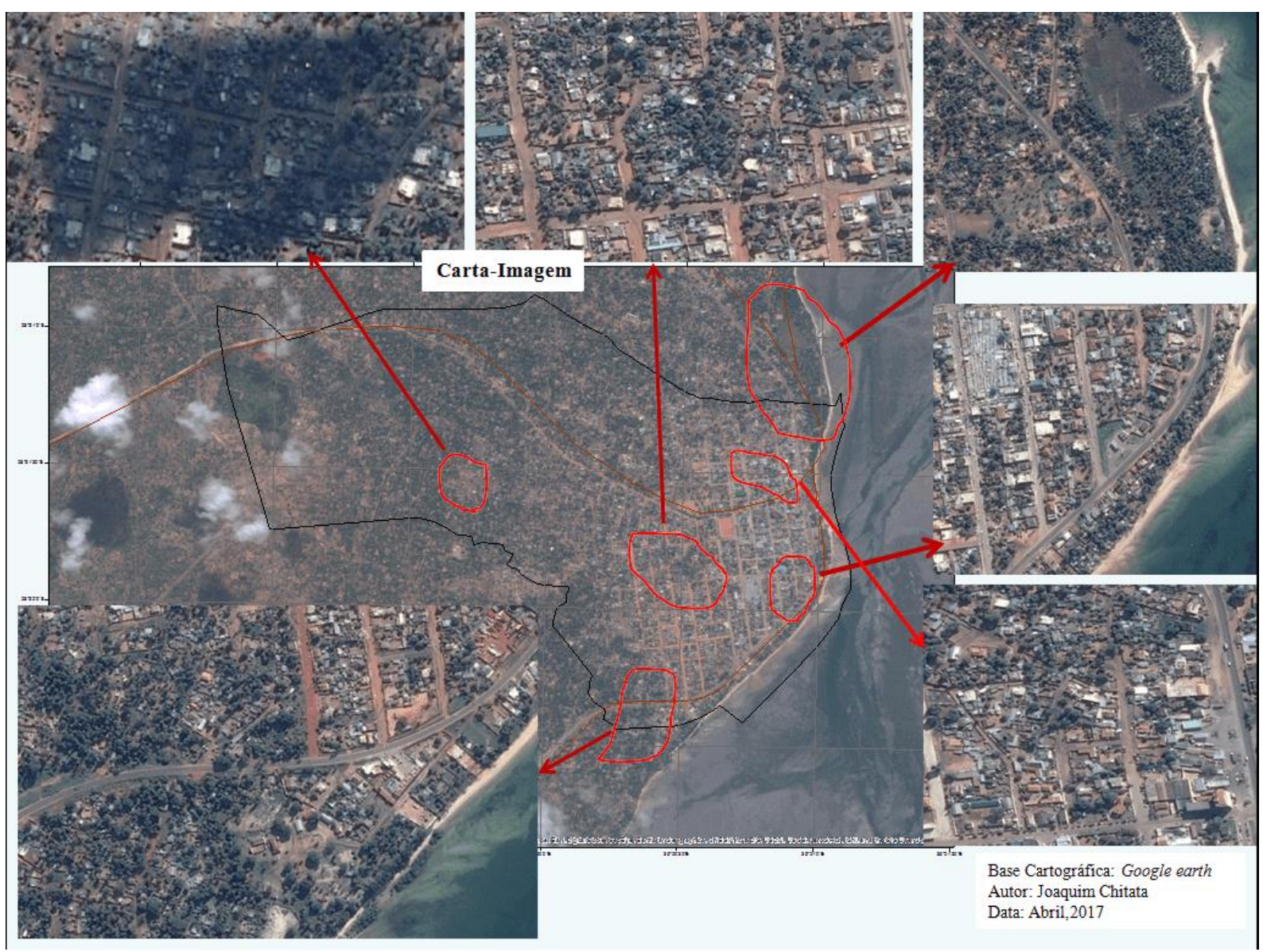

Fonte: Autor (2017)

Por fim, é importante salientar que os extremos nordeste, centro-oriental, meridional e interior mais a sudoeste são áreas ocupadas pela maioria da população desfavorecida de classe média e baixa. A maior parte das habitações nestes locais são de material constituído por caniço-madeira-zinco, folhas de coqueiro, considerados relativamente baratos e acessíveis, se comparados com os convencionais (para construção de alvenarias). Nota-se, também, que estas áreas, em alguns casos, estão desprovidas de um planeamento físico do meio com requisitos básicos, concorrendo, dessa forma, para a proliferação de mais criadouros. 


\section{CONSIDERAÇÕES FINAIS}

Diante dos resultados apresentados e discutidos neste artigo, naturalmente, estão distante de se esgotar, pulsos de uma longa e intensa atividade de pesquisa, caracterizada por muitos obstáculos e contrariedades e com o objetivo de avaliar a espacialização do risco de malária com base em dados de áreas residenciais por tipo de criadouros no bairro Chambone, foi possível perceber que: o alto risco de malária, em determinadas áreas do bairro Chambone, está associado à existência de criadouros, condições domiciliares/habitacionais precárias e ao tempo de exposição ao vector causador da malária. Estas áreas de alto risco estão associadas à mais outros fatores, como as condições físico-geográficas (localização próxima aos ambientes naturais de espécies anofélicas) e socioeconômicas (assentamentos informais e condições de saneamento precário do meio).

Em Moçambique, a malária é endêmica em todo território e a maior parte da população vive em áreas de alto risco à infecção malárica devido a fatores que contribuem para a endemicidade, nomeadamente: as condições climáticas e ambientais, temperaturas favoráveis, padrão de precipitação, locais propícios para a propagação do vetor, a situação socioeconômica da maior parte da população relacionada com a pobreza, habitações inapropriadas e meios de prevenção inacessíveis (PNCM, 2007). A avaliação do risco de malária no bairro Chambone passou, primeiro, pela caracterização socioambiental e obtenção de criadouros ou focos de malária e, em seguida, fez-se a identificação de áreas de risco. Ligado a isto esteve a produção de mapas de espacialização de risco de malária no bairro Chambone. Foram algumas das questões que perpassaram este estudo.

Esta geração de produtos cartográficos para ilustrar a espacialização de risco de malária serve de ferramenta fundamental para as autoridades locais competentes, gestores e os agentes comunitários de saúde, permitindo a definição de ações de mitigação e controle nas áreas consideradas de alto risco de malária. 


\section{REFERÊNCIAS}

ÁVILA, S. L. M. Malária. In: FERREIRA, A. W. Diagnóstico laboratorial das principais doenças infecciosas e auto-imunes. Rio de Janeiro: Guanabara Koogan, 1996.

GARCIA, F. R. M. et al. 2009. Influências ambientais na qualidade de vida em Moçambique. Disponível em: http://www.acoalfaplp.net. Acesso em: 16 mai. 2020.

MISAU - MINISTÉRIO DA SAÚDE. 2008. Moçambique. Disponível em: http://www.misau.gov.mz/pt/programas_de_saúde/malária. Acesso em: 21 jan. 2016.

NWETI. Comunicando para a Saúde. Revisão de Literatura sobre Malária, 2010.

OMS. Relatório sobre o paludismo no mundo 2014. 2014. Disponível em: http:// apps.who.int/iris/bitstream/10665/160458/3. Acesso em: 22 jan. 2016.

PNCM - Programa Nacional de Controlo da Malária. Plano Estratégico da Malária 2012 -2016. MISAU. Maputo: Direcção Nacional de Saúde Pública, 2007.

SPGC - Serviços Provinciais de Geografia e Cadastro. Shapefiles de Moçambique e do Município da Maxixe, Inhambane, 2017.

SSMAS - Serviços de Saúde, Mulher Acção Social. Relatório Anual de Maxixe. Moçambique: Maxixe, 2016.

ROLL BACK MALARIA. 2014. O Plano de Acção Global da Malária para um Mundo livre de Paludismo. Genebra: Parceria Roll Back Malaria. Disponível em: www.rollbackmalaria.org inforbm@who.int. Acesso em: 10 jun. 2016.

WHO - World Health Organization. Estratégias de Cooperação da OMS com a República de Moçambique, 2004-2008, 2004. 


\section{APÊNDICE - REFERÊNCIA DE NOTA DE RODAPÉ}

3. INE - Instituto Nacional de Estatística; ${ }^{2} \mathrm{CMCM}$ - Conselho Municipal da Cidade de Maxixe; ${ }^{3}$ SDSM - Serviços Distritais de Saúde de Maxixe; ${ }^{4}$ CENACARTA - Centro Nacional de Cartografia e Teledetecção; ${ }^{5} \mathrm{SPGCl}$ - Serviços Provinciais de Geografia e Cadastro de Inhambane.

Enviado: Março, 2020.

Aprovado: Maio, 2020. 